\title{
Developing The Self-Directed Learning Instructional Model To Enhance English Reading Ability And Self-Directed Learning Of Undergraduate Students
}

Saovapa Wichadee, Bangkok University, Thailand

\begin{abstract}
The purposes of this study were to develop the instructional model for enhancing self-directed learning skills of Bangkok University students, study the impacts of the model on their English reading comprehension and self-directed learning ability as well as explore their opinion towards self-directed learning. The model development process consisted of a review of literature, the design of the learning model, and evaluation of its effectiveness by experts'validation and implementation of the model in the classroom. The research instruments included 1) the Honey and Mumford's Learning Style Questionnaire used to divide the students into four groups: activist, reflector, theorist, and pragmatist, 2) self-directed learning readiness scale created by Guglielmino, 3) a reading comprehension test, and 4) an opinion questionnaire towards selfdirected learning. Over 12 weeks, the designed Self-directed Learning Instructional Model was employed with 120 students enrolled in Fundamental English I course in the first semester of 2010 academic year. Then the data were analyzed by mean, standard deviation, t-test, and One-way Analysis of Variance. Regarding the effectiveness of instructional model, the experts accepted that the model was appropriate. From implementing the model in class, it was found that the English reading proficiency mean scores of the post-test of students in four learning styles were significantly higher than those of the pre-test ( $p<.05)$. Moreover, the post-test mean scores of selfdirected learning ability of students in four learning styles were significantly higher than the pretest mean scores ( $p<.05)$. The students had a high level of opinion towards self-directed learning. The findings suggest that self-directed learning environment be provided for students to enhance their reading skill and self-directed learning ability.
\end{abstract}

Keywords: Self-Directed Learning; Reading Skill; Learning Styles; Language Learners

\section{INTRODUCTION}

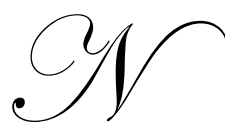

owadays English is considered as one of the most important subjects in the Thai educational system. Therefore, it has been a compulsory subject and chosen as a foreign language for Thai students at the primary, secondary, and university levels. Thai students need to learn English in order to use all four skills effectively. Among the four language skills, reading is considered to be the most important skill for English language learners. It supports the development of overall proficiency and provides access to crucial information when students further their study, especially at the university level (Komiyama, 2009: 32). They need good reading skill for acquiring knowledge and learning new information. However, we can see that most students' reading abilities are not good enough to do so. Even reading comprehension skills of students at the upper secondary level are below the eighty percent criterion (Youngjermjantra, 1994). Hence, many researchers have been interested in doing research to investigate appropriate reading strategies to help students have better understanding when they read. Many reading methods have been used in classrooms alternately. The results show that some are successful with a particular group of students, but some are not. 
Actually, what should be taken into consideration now is the way the knowledge is presented. As we know, teacher-centered approach taking place in traditional classroom cannot produce active recipients and results in fossilized language learning. From this perspective, learning should be student-centered, self-directed as far as possible, problem-based where appropriate, and collaborative in nature. This means that the teaching approaches adopted by the course should be group work, problem solving tasks, collaborative tasks, individual and group presentations, concept mapping and concept development activities, case studies and a range of other strategies associated with a student-centered approach to teaching and learning. In organizing the effective instruction, it is necessary to consider three important factors namely: learners, instructors, and learning process. For the learner factor, teachers have to think of individual differences such as students' IQ and learning style. For example, if the teaching method corresponds with students' learning style, this will help to promote their learning motivation and learning achievement. Therefore, teachers need to develop instructional process for enhancing learners' accomplishment. That is, the process the teachers design should be effective enough to promote the students' potentials and they need to use a wide variety of language inputs, activities, and materials in their classes.

According to the National Education Act of 1999: Section 24 stating that "In organizing the learning process, educational institution and agencies concerned shall (1) provide substance and activities in line with the learners' interests and aptitudes, bearing in mind individual differences," the teaching and learning process, then, aims at enabling the learners to develop themselves at their own pace and to the best of their potentiality. This means that, in organizing instruction, learning style is one factor that should be taken into consideration. Using an appropriate teaching method with learners' learning style will help to promote their motivation to learn and enhance their learning potentials, leading to higher learning achievement (Brown, 1994). Therefore, instructors need to develop instructional strategies or models due to the learners' desire.

Another point that has played an important role on students' learning, especially in higher education, is self-directed learning, one educational goal of the nation. Thailand has long been attempting to foster autonomous learning in educational practice. We can see that this kind of learning has been extensively enforced since it was stipulated in the National Education Act of 1999 (Thamraksa, 2003). According to Peter (2000), there will be greater emphasis placed on the ability to learn and to continue to learn independently and autonomously. He also states that the trend in learning and teaching in any universities will be oriented to the principles of continuing education and lifelong learning more than before. Self-directed learning is more likely to become true at the university level than any other levels such as primary and secondary school because university students have more freedom to select things they like, for example; subjects or study time. So, they should be able to study on their own to seek for knowledge and direct themselves appropriately to achieve the goal. The concept of self-directed learning has great benefits due to the fact that whenever students are aware of some needs for learning, they will continue their studies without being controlled by the others. The researcher believes that if self-directed learning is incorporated into a part of English course, it will enhance students' life-long learning skill. Also, many studies demonstrate the effectiveness of self-directed learning models that they can help improve students' language proficiency as well as their self-directed abilities in the field of language teaching and others such as Suwannasilp (2000), Wattananamkul (2001), Pornpan (2003), Saha (2006), Kim (2010), and Phongnapharuk (2007). The findings from these studies have documented the need for students to be prepared for the rapidly changing environment.

As the reasons stated earlier, the researcher would like to develop the self-directed model to use with Bangkok University students in order to enhance their reading proficiency and self-directed learning abilities. The instructional model was thus designed to support the concept of individual differences, student-centered learning and life-long learning skill. Therefore, students' learning styles have been taken into consideration when the model was constructed. This is for a better understanding of how much students in each learning style can acquire their language proficiency, gaining insights into how to further develop their ability and self-directed learning skill. The results of the study are expected to be significant in many aspects. In terms of theoretical contributions, the findings can provide more insights on how the self-directed learning model is useful for the development of reading process. In terms of practical contributions, the findings lead to a new pattern of learning that increases the students' reading proficiency and motivation to learning. That is, there is an alternative way for any instructors who are interested in developing the model to suit their own setting. 


\section{OBJECTIVES OF THE RESEARCH}

This study contains four main research objectives as follows:

1. To develop the Self-directed Learning Instructional Model for increasing English reading ability of Bangkok University students

2. To study the effects of Self-directed Learning Model on English reading ability of Bangkok University students

3. To study the effects of Self-directed Learning Model on self-directed learning ability of Bangkok University students

4. To examine the students' opinions towards self-directed learning for enhancing their reading ability.

\section{RESEARCH METHODOLOGY}

\subsection{Population And Samples Research Design}

This study was based on one group pretest posttest experimental design. The population in this study included 5,240 first-year students enrolled in EN 111 course in the first semester of 2010 academic year. As the students were already assigned in groups by the institution, three sections were chosen by cluster sampling for the treatment. The samples were 120 students from three sections, each of which contained 40 students from the School of Communication Arts. The three sections were assigned to same treatment: self-directed learning. Then, the learning style scores were used to group students into four groups namely activist, pragmatist, theorist, and reflector.

\subsection{Research Instruments}

\subsubsection{Self-Directed Learning Readiness Scale Or SDLRS}

The instrument most widely used in educational research to measure self-directed learning readiness created by Guglielmino's (1977) was employed in this study. SDLRS is a 58-item and the questions are pertained to 8 factors were labeled as follows: 1) Openness to learning opportunities 2) Self-concept as an effective learner 3) Initiative and independence in learning 4) Informed acceptance of responsibility for one's own learning 5) A love to learn 6) Creativity 7) Future orientation 8) The ability to use basic study skills and problem-solving skills. It is a five-point Likert-type rating scale questionnaire designed to measure a degree to which learners perceive themselves as having the skills of self-directed learning, ranging from almost always true to almost never true. The criteria of interpretation or the meaning of each range is as follows: $1.00-1.50=$ the least, $1.51-2.50=$ less, $2.51-3.50=$ average, $3.51-4.50=$ more, $4.51-5.00=$ the most. The instrument was validated by 3 experts and piloted with 40 non-subject students to check readability and understanding of the items. The data of the questionnaire from the pilot group was processed for determining an internal consistency reliability coefficient. The alpha-coefficient value of .789 indicated a high reliable of the questionnaire.

\subsubsection{A Learning Style Questionnaire}

Honey and Mumford's Learning Style Questionnaire (1992) was administered to the students to investigate their preferred learning styles. This questionnaire was a kind of checklist. All of the items are related to how the students perceive their learning styles comprising activist, reflector, theorist, and pragmatist. The questionnaire consisted of totally 40 items, whereas 10 items denote to each type of learning style. Their preferred learning styles were identified as presenting a strong (Band A) to low (Band D) preference using the general norms given by Honey and Mumford. Those students gaining scores in Band A identify more strongly with that style than those in Band B and so on. The band in which the student scored the highest was used to classify their learning style. As a result, the study got 41 pragmatists, 31 theorists, 26 activists and 22 reflectors. Even though the questionnaire had been widely used in many pieces of research, to make sure of its content validity, the items in the questionnaire were rated again by three experts who have keen experienced in teaching English for more than 5 years. To determine validity, each item must get a score more than 80 percent, and all of the experts (100\%) agreed that the items can be used for measuring a specific learning style pattern of learners. After that, the validated learning style inventory was 
processed for determining its reliability with 40 non-subject students by the coefficient alpha technique. The result was highly reliable with the Cronbach alpha coefficient of .814 .

\subsubsection{An Opinion Questionnaire Towards Self-Directed Learning}

This questionnaire was used to investigate how the students felt about self-directed learning. It consisted of 16 items. The five-point rating scale ( $1=$ strongly disagree, $2=$ disagree, $3=$ neither agree nor disagree, $4=$ agree, and $5=$ strongly agree) was used for a post-study survey. The draft questionnaire was created with 24 items which were later checked for their content validity by three experts in English teaching field based on the Item-Objective Congruence (IOC) Index. The items with IOC index higher than 0.5 were acceptable. Therefore, only 16 items could be reserved. In order to test the proper reliability of the questionnaire, the questionnaire was piloted with 40 undergraduate students during the first semester of academic year 2009 at Bangkok University and calculated for proper reliability value by using Cronbach's Coefficient Alpha. The value of the overall questionnaire was .730.

\subsubsection{The Reading Test}

The reading comprehension test, which consisted of 50 multiple-choice items with four alternatives, was created to use as the pre-and post-tests and to measure students' achievement. The content was based on course description of the curriculum which covered reading comprehension ability in applying the language and study skills to read at the cognitive level. It involved applying the knowledge of textual schemata or the structural characteristics of written content and recognizing key information of the content so as to extract the main ideas, major and minor supporting details in organizing notes, identifying facts, making inferences, drawing a conclusion and writing a summary. Time allowed for the test is 100 minutes.

\subsection{Data Collection}

Prior to the instruction (week 1), the researcher introduced the steps of instructional process, learning procedures, learning resources, evaluation process, and learners' roles and to make sure that they understood the experimental process. Students were also surveyed their needs of reading skills. After that, the students took a pretest of reading. Then a questionnaire of self-directed learning readiness scale was administered first to collect the data on students' self-directed learning ability. To determine each person's learning style, the students were asked to complete an instrument called Learning Style Questionnaire (LSQ) based on the Honey and Mumford Learning Style Model. The result was used to divide them into four groups called activist, reflector, theorist, and pragmatist. A survey of students' need of reading skill was done by a survey sheet.

On the second week, each student planned his/her learning project with the researcher's suggestion. Students were asked to write a learning contract in which they stated their specific objectives over a limited period. In other words, on several occasions each SDLI group developed a learning contract project and then attempted to implement that contract. The purpose of using the contract was to encourage self-directed learning, while still balancing individual and group learning styles. The contract in this study was organized based on the questions drawn from McGarrell's work (1996), cited in Al-Dossary (2002).

A target date for completion of ten weeks from the preparation of the contract was assigned, and all students were asked to sign the one-page contracts after indicating the total amount of time they planned to spend each day (outside of class) on assignment. At the same class session, students were given a one page handout, Progress Report 1 on Learning Contract 1, to be handed in one week later with responses to the following questions:

- My comments on this self-directed learning process: How did it work?

- What help do I need now?

- Do I want to change my original learning contract in any way? If so, how?

A further progress report was requested each time every two weeks.

Teaching and learning process was conducted for 12 weeks. 
After the instruction, the students did the reading post-test and checked opinions towards self-directed learning. Then they completed the self-directed learning readiness scale at the end of the course.

\section{RESEARCH RESULTS}

\subsection{The Self-Directed Learning Instructional Model Designed For EN111 Students}

The Self-directed Instructional Model derived from this study consisted of three stages as follows:

Preparation stage consisted of making a survey of students' needs in reading skills to diagnose their background knowledge, and data were used as guideline for teaching them. By doing this, the teacher can provide them with necessary reading strategies.

Learning stage comprised seven steps namely, choosing the contents of their interest, stating learning objectives, creating a learning project and contract, planning to achieve the goal, engaging in learning activities, synthesizing the knowledge acquired, and evaluating learning outcomes.

Evaluation stage included three kinds of assessment: 1) examining the students' reading ability, 2) investigating the students' self-directed learning ability, and 3) studying the students' opinion toward self-directed learning.

\subsection{Results Of The Experiment}

Research Question 1: To what extent does the Self-directed Learning Instructional Model improve English reading ability of Bangkok University students?

Table 1: A Comparison Of Pre- And Post- Reading Mean Scores

\begin{tabular}{|c|c|c|c|c|c|c|}
\hline & $\bar{X}$ & S. D. & $\mathbf{n}$ & $\mathbf{t}$ & Sig & g \\
\hline Pre-Test & 23.59 & 6.58 & 120 & 23.08 & .001 & .18 \\
\hline Post-Test & 31.14 & 6.22 & 120 & & & \\
\hline
\end{tabular}

From a t-test analysis, English reading comprehension post-test mean score of the students was significantly higher than the pre-test mean score $\mathrm{t}(119)=23.08, \mathrm{p}<.05$. This means that the students improve their reading comprehension through self-directed learning after 12 weeks of the treatment. Therefore, this hypothesis was accepted. The effect size of these two mean scores was calculated, and the result suggested that the improvement was very small $(\mathrm{g}=0.18)$.

Research Question 2: Can the Self-directed Learning Instructional Model enhance the students' reading ability in the four groups of learning styles? If yes, to what extent does it improve their reading ability?

This research question explores the students' English reading score improvement in four groups after the intervention. To investigate the improvement of English reading comprehension in details, the examination of the English reading comprehension scores was calculated for mean, standard deviation, and dependent t-test analysis in the four learning styles namely activist, pragmatist, theorist, and reflector.

Table 2: Comparisons Of Pre- And Post- Reading Mean Scores Of The Students Shown In Four Learning Styles

\begin{tabular}{|c|c|c|c|c|c|c|c|}
\hline \multirow{2}{*}{ Learning Style } & \multicolumn{2}{|c|}{ Pre-test } & \multicolumn{2}{|c|}{ Post-test } & \multirow{2}{*}{ Sig } & \multirow{2}{*}{$\mathbf{g}$} \\
\cline { 2 - 6 } & $\bar{X}$ & S.D. & $\bar{X}$ & S.D. & & & .22 \\
\hline Activist $(\mathrm{n}=26)$ & 21.19 & 6.37 & 30.08 & 6.46 & 11.18 & .001 & .22 \\
\hline Pragmatist $(\mathrm{n}=41)$ & 25.39 & 7.28 & 32.44 & 7.19 & 13.03 & .001 & .13 \\
\hline Theorist $(\mathrm{n}=31)$ & 23.22 & 6.19 & 30.45 & 5.31 & 11.89 & .001 & .21 \\
\hline Reflector $(\mathrm{n}=22)$ & 23.59 & 5.32 & 30.95 & 5.02 & 10.37 & .001 & .27 \\
\hline
\end{tabular}


Hypothesis 1: The English reading post-test scores of the students studying with the Self-Directed Learning Instructional Model in the four groups will be significantly higher than the pre-test scores.

Table 2 demonstrates the mean scores of the reading tests classified in four groups. Among four groups, students were in the pragmatist group the most. The pragmatists had the highest mean scores in both pre- and posttests. The table also shows that the mean scores of students in four learning styles improved significantly after the experiment $(\mathrm{P}<.05)$. This means that all learning styles can be best improved by self-directed learning. Therefore, the Hypothesis 1 was accepted. The effect size of the pre-and post- test mean scores using Hedge's 'g' suggested that the difference was small in all groups of learning styles.

To find out whether a difference existed in students' reading comprehension scores among the four learning style groups before the intervention, the mean scores of the pre-test were compared using One-way ANOVA.

Table 3: A Comparison Of Reading Mean Scores Among The Four Groups Of Students Before The Intervention

\begin{tabular}{|c|c|c|c|c|c|}
\hline Source & SS & df & MS & F & p \\
\hline Between groups & 286.460 & 3 & 95.487 & 2.270 & .084 \\
\hline Within groups & 4880.532 & 116 & 42.074 & & \\
\hline Total & 5166.992 & 119 & & & \\
\hline
\end{tabular}

From Table 3, the pre-test mean scores obtained from the four learning style groups: activists, theorists, and reflectors were analyzed, and the result shows that there was no statistically significant difference in the reading ability among the four groups before the intervention. To further investigate the difference among the four groups of learning style in terms of their post reading ability, One-way ANOVA was used to analyze the data.

Table 4: A Comparison Of Reading Mean Scores Among Four Groups Of Students After The Intervention

\begin{tabular}{|c|c|c|c|c|c|}
\hline Source & SS & Df & MS & F & p \\
\hline Between groups & 114.016 & 3 & 38.005 & .981 & .404 \\
\hline Within groups & 4492.576 & 116 & 38.729 & & \\
\hline Total & 4606.592 & 119 & & & \\
\hline
\end{tabular}

The result from Table 4 shows that the four groups with different learning styles did not have a significant difference in reading ability after they studied in the self-directed learning environment at the 0.05 level. This means that the four groups of learning styles did not demonstrate different reading ability.

Research Question 3: To what extent does the Self-directed Learning Instructional Model improve self-directed learning ability of Bangkok University students?

Table 5: A Comparison Of Pre- And Post- Self-Directed Learning Mean Scores

\begin{tabular}{|l|c|c|c|c|c|c|}
\hline & $\bar{X}$ & S.D. & n & t & Sig & g \\
\hline Pre-Questionnaire & 200.79 & 17.09 & 120 & 9.45 & .001 & .05 \\
\hline Post-Questionnaire & 213.57 & 16.61 & 120 & & & \\
\hline
\end{tabular}

From a t-test analysis, self-directed learning mean score of the students after the intervention was significantly higher than that before the instruction $\mathrm{t}(119)=9.45, \mathrm{p}<0.05$. This means that the students improve their self-directed learning abilities through self-directed learning after 12 weeks of the treatment. An effect size of the pre-and post-questionnaire mean scores was very small $(\mathrm{g}=0.05)$.

Research Question 4: Do students in the four groups of learning styles improve their self-directed learning ability after learning with the SDLI Model? If yes, to what extent? 
Table 6: Comparisons Of Pre- And Post- Of Self-Directed Learning Ability Shown In Four Learning Styles

\begin{tabular}{|c|c|c|c|c|c|c|c|}
\hline \multirow{2}{*}{ Learning Style } & \multicolumn{2}{|c|}{ Pre-Test } & \multicolumn{2}{|c|}{ Post-Test } & \multirow{2}{*}{ Sig } & \multirow{2}{*}{ g } \\
\cline { 2 - 7 } & $\overline{\mathrm{X}}$ & S.D. & $\overline{\mathrm{X}}$ & S.D. & & & \\
\hline Activist $(\mathrm{n}=26)$ & 203.11 & 14.61 & 209.00 & 14.69 & 6.20 & .001 & .02 \\
\hline Pragmatist $(\mathrm{n}=41)$ & 206.58 & 16.04 & 219.39 & 15.19 & 5.30 & .001 & .05 \\
\hline Theorist $(\mathrm{n}=31)$ & 191.03 & 17.88 & 211.45 & 16.09 & 6.18 & .001 & .07 \\
\hline Reflector $(\mathrm{n}=22)$ & 201.00 & 15.51 & 211.14 & 19.82 & 4.30 & .001 & .03 \\
\hline
\end{tabular}

Hypothesis 2: After the intervention, the self-directed learning ability of the students in the four groups will be significantly higher than before the intervention.

Table 6 shows a significant increase of self-directed learning ability. Students in the four learning styles developed their self-directed ability at a significance level of .05. So, this hypothesis was accepted. However, the effect size was very small in all groups. To find out whether there was a difference in students' self-directed learning ability among the four learning style groups before the intervention, the mean scores of the prequestionnaire were compared using One-way ANOVA.

Table 7: A Comparison Of Self-Directed Learning Mean Scores Of The Students Before The Intervention

\begin{tabular}{|c|c|c|c|c|c|}
\hline Source & SS & df & MS & F & p \\
\hline Between groups & 4470.219 & 3 & 1490.073 & 5.709 & .001 \\
\hline Within groups & 30275.573 & 116 & 260.996 & & \\
\hline Total & 34745.792 & 119 & & & \\
\hline
\end{tabular}

The result shows that before the intervention students with different learning styles had different selfdirected learning ability at the significance level of .05. Post Hoc analysis was further conducted to compare each pair, and it was found that significant differences were found in three pairs. This means, self-directed learning ability of the theorists was significantly different than that of the activists, pragmatists, and reflectors. (See Table 8 below)

Table 8: Test Of The Mean Scores Of Self-Directed Learning Ability

\begin{tabular}{|c|c|c|c|c|}
\hline Group & $\begin{array}{c}\text { Activist } \\
(\bar{X}=\mathbf{2 0 3 . 1 1})\end{array}$ & $\begin{array}{c}\text { Pragmatist } \\
(\bar{X}=\mathbf{2 0 6 . 5 8})\end{array}$ & $\begin{array}{c}\text { Theorist } \\
(\bar{X}=\mathbf{1 9 1 . 0 3})\end{array}$ & $\begin{array}{c}\text { Reflector } \\
(\bar{X}=\mathbf{2 0 1 . 0 0})\end{array}$ \\
\hline Activist $(\bar{X}=203.11)$ & & & $12.08^{*}$ & \\
\hline Pragmatist $(\bar{X}=206.58)$ & & & & $9.55^{*}$ \\
\hline Theorist $(\bar{X}=191.03)$ & & & & \\
\hline Reflector $(\bar{X}=201.00)$ & & & \\
\hline
\end{tabular}

$* \mathrm{P}<.05$

Table 9: A Comparison Of Self-Directed Learning Mean Scores Of The Students After The Intervention

\begin{tabular}{|c|c|c|c|c|c|}
\hline Source & SS & df & MS & F & p \\
\hline Between groups & 2201.301 & 3 & 733.767 & 2.778 & .050 \\
\hline Within groups & 30642.000 & 116 & 264.155 & & \\
\hline Total & 32843.300 & 119 & & & \\
\hline
\end{tabular}

The self-directed learning mean scores obtained from the four learning groups after the intervention were compared using One-way ANOVA. The results show that the ability of the four groups was not significantly different at the 0.05 level $(\mathrm{p}=.05)$. This means that the students in the four groups did not report different levels of self-directed learning ability. 
Research Question 5: What are the opinions of the students towards the SDLI Model?

The overall mean score of opinion toward self-directed learning was at a high level ( $\bar{X}=4.08$ ). Among 16 items, the third highest mean scores were "A learning project makes me feel like having more participation", followed by "I have more decision on how to learn by this learning", and "Writing a report about what I have studied from different sources helps me to conclude my knowledge well" respectively ( $\bar{X}=4.23,4.19$, and 4.18). These items were at a high level. The lowest mean score was "This kind of learning encourages me to acquire knowledge on my own", which was also at a high level $(\bar{X}=3.93)$.

Hypothesis 3: The students are likely to have positive opinions towards the Self-Directed Learning Instructional Model (Mean of opinion scale $\geq 3.5$ from the five-point rating scale).

Table 10: A Comparison Between The Students' Opinion And The Set Criteria

\begin{tabular}{|c|c|c|c|c|c|}
\hline Variable & $\bar{X}$ & S.D. & Criteria & t & p \\
\hline Opinion & 4.08 & .307 & 3.50 & 20.795 & .000 \\
\hline
\end{tabular}

The result from one sample t-test analysis shows that the grand mean score of 4.08 was higher than 3.50 at the significance level of .05. Consequently, Hypothesis 3 was accepted.

\section{DISCUSSION OF THE RESULTS}

\subsection{The Effects On The Students' English Reading Comprehension Ability}

Research question 1 studied the improvement on reading comprehension. The comparison between the mean scores of English reading comprehension pre-and post-tests show that the students significantly improved their reading ability. The Self-directed Learning Instructional Model might be an efficient way for teaching reading skills. This is in consistent with other studies in which self-directed learning helped increase the learners' reading scores (Lee, 1998; Phongnapharuk, 2007; Kim, 2010). By exposing students to self-directed learning where they had their own selection of learning contents and methods to achieve their learning goal, they could gain reading fluency and comprehension. A learning contract is a successful learning tool to promote students' responsibility. This means the students understand the need to learn something -- how it will benefit them if they depend on it or what the consequences will be if they do not before they are willing to invest time and energy. They see the benefits of taking charge of their own learning since the traditional method of teaching blocked the learning capacity; they were not given an opportunity to set the goal for their learning. According to Littlewood (1996), to be successful, students need the ability and willingness to assume learning responsibility. The ability includes both the knowledge and skills for carrying out whatever choices they see appropriate for their learning. Willingness comes from the motivation and the confidence that the learners have for taking responsibilities in their learning. So, the students in this study could adjust themselves well to the new teaching and learning context; they tend to accept what they wrote in the contract. The result was in accordance with Knowles's concept (1986, p. 41), stating that a learning contract involves the learners in making decisions about what will be learned, how it will be learned, when it will be learned, and whether it has been learned, usually with the help of a facilitator or resource person. The score increase, therefore, proves that unskilled readers can become skilled readers if they are given effective strategy instruction and taught to monitor and check their comprehension while reading.

Actually, students in most classes vary greatly in background such as readiness and learning styles. Research question 2, therefore, investigated which learning styles can be improved significantly after getting the treatment. The results showed the effectiveness of Self-directed Learning Instructional Model which can improve all styles of learning. This is probably because self-directed learning provides an opportunity for the learners to choose their own reading materials as well as set their own objectives to learn. This kind of learning is suitable for various learning styles. In this model, students could pick what suited them the best such as working in groups, individually or in pairs. In addition, they were able to set their learning objectives and choose the contents in which they felt 
interested to learn. The more ways students have or choose, the more they succeed. According to the results, the model can significantly improve the students' reading ability extensively in all learning styles, especially pragmatists and activists. This is probably because activists are likely to learn best from opportunities to work with other people, or as part of a team, flexible situations without the constraint of rules and guidelines, the opportunity to tackle problems 'head-on', and new challenges and experiences (Honey\& Mumford, 2000). In this study, students were allowed to work both in pairs and individually during the experiment. Therefore, the class activities and format might interest them and thus improve their reading comprehension. For pragmatists, they are likely to learn best from understanding the real world application, the opportunity to try things out, having a clear structured plan with a definable purpose. This implies that students in all learning styles can be encouraged in self-directed learning environment to obtain the potential benefits of reading comprehension improvement.

\subsection{The Effects On Self-Directed Learning Ability}

Research question 3 examined effects of the model on students' self-directed learning ability, and it was found that self-directed learning mean score of the students was significantly improved. This might be due to the fact that the procedure in the learning process management gave them the authority to design their learning projects and set learning objectives, and students in higher education level are mature enough to do so. By this way, it enabled them to take charge of their own learning and gain better results. Given the opportunity to have more decision on their learning, students learned that they could direct themselves to achieve the goal. This is a way to make them feel more confident and have a trust in what they are doing. They were not only ready to learn independently, but also at risk of the deterioration of the development of learner autonomy. Being similar to what was found in two studies (Phongnapharuk, 2007; Pornpan, 2003), the present finding can draw a conclusion that self-directed learning skill can be learned and taught with certain techniques. In this study, the use of learning projects and contracts could help students construct knowledge through active involvement in assessing their own learning performance; therefore, students are empowered by gaining ownership of their learning and life-long learning skills (Chen, 2008). The increase in self-directed learning ability indicates that students improved their ability and willingness to assume learning responsibility (Littlewood, 1996). They developed the knowledge and skills for carrying out whatever choices they saw appropriate for their learning.

Research question 4 studied which group of learning styles could significantly improve their self-directed learning ability after the treatment. It was found that students in all groups significantly improved their self-directed learning ability at the .05 level. This is probably because the study placed an importance on individual difference and all learning activities were organized based on the students' needs. The positive result informs that self-directed learning can be developed with the highest opportunity when learning conditions are interrelated. In this study, a learning contract is like a guideline for their destination. They can use this goal to monitor their reading and to maintain their reading motivation. Moreover, it is interesting to note that students usually set a goal that is practical and achievable. The reason behind their choices can be explained by their differed characteristic. However, it is noted that the theorists gained much more self-directed learning ability than the other three groups, so no significant differences existed in self-directed learning ability among the four groups after the treatment. This might be because the theorists are normally disciplined. They prefer to think of problems in a step-by step manner (Coffield et al., 2004). When they were taught with this learning model, they could improve their self-directed learning quite well. Different students have different abilities to be self-directed although they got the same development of selfmanagement skills. In this study, students participated in all aspects of learning and decision making; for example, in supplying material, choosing a course's content and learning strategies as well as taking part in evaluation procedures. Therefore, it might be concluded that this treatment had an effect on students differently depending on their learning styles.

\section{ACKNOWLEDGMENT}

The researcher would like to thank Bangkok University for the fund granted and the students participating in this study for their cooperation and dedication. 


\section{AUTHOR INFORMATION}

Assoc. Prof. Saovapa Wichadee is now working as a full-time lecturer at the Language Institute, Bangkok University, Thailand. Her research interest includes teaching methodology in EFL, learners' characteristics, and teacher self-development. She has experienced in writing many textbooks and instructional materials, such as Writing for Business Purposes, English for Art and Design, and Business Conversation. E-mail: saovapa.w@bu.ac.th

\section{REFERENCES}

1. Al-Dossary, K. (2002). An HRD English language center. Paper presented at the 8th Annual TESOL Arabia International Conference: Critical Reflection and Practice, 20-22 March. Abu Dhabi, United Arab Emirates.

2. Brown, H. (1994). Principles of learning and teaching. NJ: Prentice Hall Regents.

3. Chen, Y. M. (2008). Learning to self-assess oral performance in English: A longitudinal case study. Language Teaching Research, 12(2), 235-262.

4. Coffield, F., Moseley, D., Hall, E., Ecclestone, K. (Ed.) (2004). Learning styles and pedagogy in post-16 learning: A systematic and critical review. Wiltshire: Learning and Skills Research Centre.

5. Guglielmino L.M. (1977). Development of the self-directed learning readiness scale. Doctoral dissertation, University of Georgia.

6. Honey, P. \& Mumford, A. (1992). The manual of learning styles. Maidenhead: Peter Honey.

7. Honey, P. \& Mumford, A. (2000). The learning styles helper's guide. Maidenhead: Peter Honey Publications.

8. Khomson, K. (1997). The development of a self-directed learning model in English reading comprehension for upper secondary school students. Doctoral Dissertation, Chulalongkorn University, Bangkok, Thailand.

9. Kim, Rosemary. (2010). Self-directed learning management system: Enabling competency and selfefficacy in online learning environments. Dissertation. The Claremont Graduate University, 2010, 130 pages; AAT 3416905.

10. Knowles, M. S. (1986). Using learning contracts. San Francisco, CA: Jossey-Bass Inc., Publishers.

11. Komiyama, R. (2009). CAR: A means for motivating students to read. English Teaching Forum, 47(3), 3237.

12. Lee, I. (1998). Supporting greater autonomy in language learning. ELT Journal, 52(4), 282-290.

13. Littlewood, W. (1996). Autonomy: An autonomy and a framework. System, 24(4), 427-435.

14. Peter, O. (2000). The transformation of the university into an institution of independent learning in changing university teaching. London: Kogan Page Limited.

15. Phongnapharuk, Chanida. (2007). Applying metacognitive strategies via computer- assisted language learning to enhance English reading, summary writing abilities and self-directed learning of expanding level students. MA. Thesis. (Teaching English as a Foreign Language), Chiangmai University.

16. Pornpan, A. (2003). A study of Readiness in self-directed learning, Learning Achievement in Psychology, and Satisfaction of Students at Boromrajchonanee Nakorn Lampang in On-line Assessment Learning. (online) Available: http://sophon.Bcnlp.ac.th/ research-lp/abstract-clearn 1 pdf. Retrieved August 13, 2005.

17. Saha, Djenta. (2006). Improving Indonesian nursing students' self-directed learning readiness. Dissertation. Faculty of Health. Queenland University of Technology.

18. Suwannasilp, S. (2000). A development of a module in Environmental Health course based on self-directed learning approach for undergraduate nursing students. Doctoral Dissertation, Chulalongkorn University, Bangkok, Thailand.

19. Thamraksa, C. (2003). Student-centered learning: Demystifying the myth. SLLT, 12, 59-70.

20. Wattananamkul, W. (2001). A development of self-directed learning system for Public Health students. Doctoral Dissertation, Konkaen University, Konkaen,Thailand.

21. Youngjermjantra, P. (1994). The ability to infer from English reading text of mathayomsuksa 4 students in schools under the Department of General Education in Pattani. M.A. Thesis, Kasetsart University. 